\title{
Diagnosis and biomarkers of predementia in Alzheimer's disease
}

\author{
Orestes V Forlenza, Breno S Diniz, Wagner F Gattaz
}

\begin{abstract}
In view of the growing prevalence of Alzheimer's disease (AD) worldwide, there is an urgent need for the development of better diagnostic tools and more effective therapeutic interventions. At the earliest stages of AD, no significant cognitive or functional impairment is detected by conventional clinical methods. However, new technologies based on structural and functional neuroimaging, and on the biochemical analysis of cerebrospinal fluid (CSF) may reveal correlates of intracerebral pathology in individuals with mild, predementia symptoms. These putative correlates are commonly referred to as AD-related biomarkers. The relevance of the early diagnosis of AD relies on the hypothesis that pharmacological interventions with disease-modifying compounds are likely to produce clinically relevant benefits if started early enough in the continuum towards dementia. Here we review the clinical characteristics of the prodromal and transitional states from normal cognitive ageing to dementia in AD. We further address recent developments in biomarker research to support the early diagnosis and prediction of dementia, and point out the challenges and perspectives for the translation of research data into clinical practice.
\end{abstract}

\section{Introduction}

Alzheimer's disease (AD) is the most common dementing disorder in older people. As a consequence of population aging worldwide, a fourfold increase in the prevalence of $\mathrm{AD}$ is expected to occur over the next decades. Recent estimates foresee that more than 80 million individuals will be affected by the disease by 2040 , which is a natural consequence of the age-dependent increase in the number of incident cases of AD [1-3]. An important contemporaneous challenge in the management of $\mathrm{AD}$ is to establish its early diagnosis, or, ideally, to identify the cases of $\mathrm{AD}$ prior to the actual onset of dementia. This requires the development of new diagnostic tools to predict the dementia outcome among older people with very mild symptoms of cognitive dysfunction, or even in asymptomatic individuals. Although a few promising methods have been experimentally validated, the translation of the current knowledge into clinical practice still requires methodological pruning and guidance by operational criteria.

The National Institute on Aging and the Alzheimer's Association have recently convened working groups to re-edit the diagnostic criteria for $\mathrm{AD}$ dementia, taking

\footnotetext{
* Correspondence: gattaz@usp.br

Laboratory of Neuroscience (LIM 27), Department and Institute of Psychiatry, Faculty of Medicine, University of São Paulo, São Paulo, Brazil
}

into account the vast expansion of the knowledge of the neurobiology of the disease, most of which was obviously unavailable by the time the original National Institute of Neurological and Communicative Disorders and Stroke-Alzheimer's Disease and Related Disorders Association (NINCDS-ADRDA) criteria were launched 26 years ago [4,5]. Another important accomplishment of these workgroups was to revise the clinical and biological correlates of $\mathrm{AD}$ in the symptomatic predementia phase, yielding the proposition of the diagnostic criteria for 'mild cognitive impairment (MCI) due to AD' [6]. The authors incorporated the use of biomarkers to define three levels of certainty of the clinical diagnosis, given the characterization of mild cognitive deficits in non-demented older people: (i) 'MCI of a neurodegenerative etiology', in the presence of the typical clinical presentation of individuals who are at an increased risk of progression to $\mathrm{AD}$ dementia, but have negative or ambiguous biomarker evidence of the underlying $\mathrm{AD}$ pathology; (ii) 'MCI of the Alzheimer type', when the subject meets the MCI criteria above and, in addition, has one or more topographic biomarkers associated with the downstream effects of the AD pathology (for example, MRI evidence of medial temporal lobe atrophy, or fluorodeoxyglucose positron emission tomography (FDG-PET) evidence of decreased temporomedial

\section{(Ciomed Central}


metabolism); and (iii) 'prodromal Alzheimer's dementia', when the subject meets the MCI criteria above and, in addition, has a positive biomarker for the molecular neuropathology of AD (such as molecular imaging of intracerebral amyloid with PET, or the typical pattern of the AD-related cerebrospinal fluid (CSF) biomarkers, as will be discussed below. The latter proposition does not require, but is reinforced by the topographic (downstream) evidence of the AD pathological process, as provided by structural or functional neuroimaging [6].

In this review article, we address the clinical characteristics of the prodromal stages of $\mathrm{AD}$ and the transitional states from normal cognitive ageing and dementia. We further present recent developments in biomarker research, and the perspectives of using these techniques to reinforce the clinical diagnosis of $\mathrm{AD}$ at predementia stages.

\section{Alzheimer's disease: translating neurobiological knowledge into clinical practice}

$\mathrm{AD}$ is a chronic neurodegenerative disease with well defined pathological markers, mostly affecting medial temporal lobe and associative neocortical structures. Neuritic plaques and neurofibrillary tangles, the pathological hallmarks of $\mathrm{AD}$, are primarily related to the overproduction and aggregation of the amyloid $\beta$ peptide $(\mathrm{A} \beta)$ within the brain, and to the hyperphosphorylation of Tau protein in affected neurons. These abnormalities lead to the activation of neurotoxic cascades and to cytoskeletal changes that eventually cause neuronal dysfunction and death. Neurofibrillary tangles appear first in allocortical structures, whereas amyloid plaques may first be found in the neocortex [7]. In addition to amyloid accumulation and neurofibrillary pathology, synaptic dysfunction leading to neuronal dystrophy are phenomena proxy to the structural changes of the brain, which ultimately triggers the clinical syndrome that characterizes incipient AD [8]. The cognitive manifestations associated with this process are compatible with subtle damage to hippocampal and related limbic and prefrontal structures, and may last for many years until the functional burden becomes severe enough to surmount the dementia threshold [9] (Figure 1).

There is evidence of a long preclinical phase in $\mathrm{AD}$, in which the aforementioned abnormalities gradually accumulate in affected brain areas prior to the presentation of significant cognitive decline and dementia. Recent models based on neuropathological, biochemical and neuroimaging methods have proposed that intracerebral amyloidosis precedes the onset of cognitive symptoms by several years, if not decades. Autopsy studies have shown that intracerebral amyloidosis may be observed in some subjects as early as in the third or fourth decades of life, with increasing magnitude in late middle age, and highest estimates in old age [10-12]. The exact proportion of amyloid-positive normal adults who will ultimately develop AD is still uncertain, and critically dependent on the age and genetics of the cohort; yet, cortical amyloid load in cognitively normal older adults seems to be associated with a higher rate of progression to symptomatic AD in the long term [13].

It is a difficult task to clinically differentiate incipient AD from normal cognitive ageing and from the subtle cognitive changes that arise in other forms of dementia in the prodromal phases. In the early stages, patients with AD may present with mild but persistent (and often progressive) cognitive deficits, albeit not severe enough to warrant the diagnosis of dementia. In the recent literature, individuals in this predementia stage of $\mathrm{AD}$ have been most commonly categorized according to the definition of MCI [14]. However, it is widely accepted today that the cross-sectional diagnosis of MCI selects a clinically and biologically heterogeneous group of patients, which limits its prognostic value [15]. Given the insidiously progressive nature of most neurodegenerative illnesses, among which $\mathrm{AD}$ represents the most prevalent condition, it is reasonable to assume that most patients who are prone to become demented will present at early stages with symptoms compatible with the definition of MCI. Nevertheless, the reciprocal assumption may not be true, given the fact that many persons who fulfill diagnostic criteria for MCI at one particular assessment will not evolve to dementia at all.

Despite this, the long predementia phase in AD constitutes a unique time frame to search for clinical and neurobiological tools to reinforce the cross-sectional diagnosis and to predict the dementia outcome. The neuropathological features of subjects with amnestic MCI are intermediate between those found in cognitively normal and demented individuals (Figure 2). In a clinicopathological study, most patients with amnestic MCI did not meet the neuropathologic criteria for AD, but their pathological findings suggested a transitional state of evolving $\mathrm{AD}$, given the involvement of medial temporal lobe structures likely accounting for the memory impairment [16].

Subtle changes related to the pathological process may be quantified in asymptomatic or mildly symptomatic patients by the assessment of humoral fluids, mostly cerebrospinal fluid (CSF), or by using advanced neuroimaging methods. Therefore, the rationale for the search for biological markers in $\mathrm{AD}$ is to increase diagnostic accuracy at early stages of the disease process. The correct use of this information may help identify subjects at risk of developing dementia upon follow-up. However, the clinical benefits will critically depend on the availability of more efficacious therapies to halt cognitive decline and, ideally, to prevent dementia. These include 


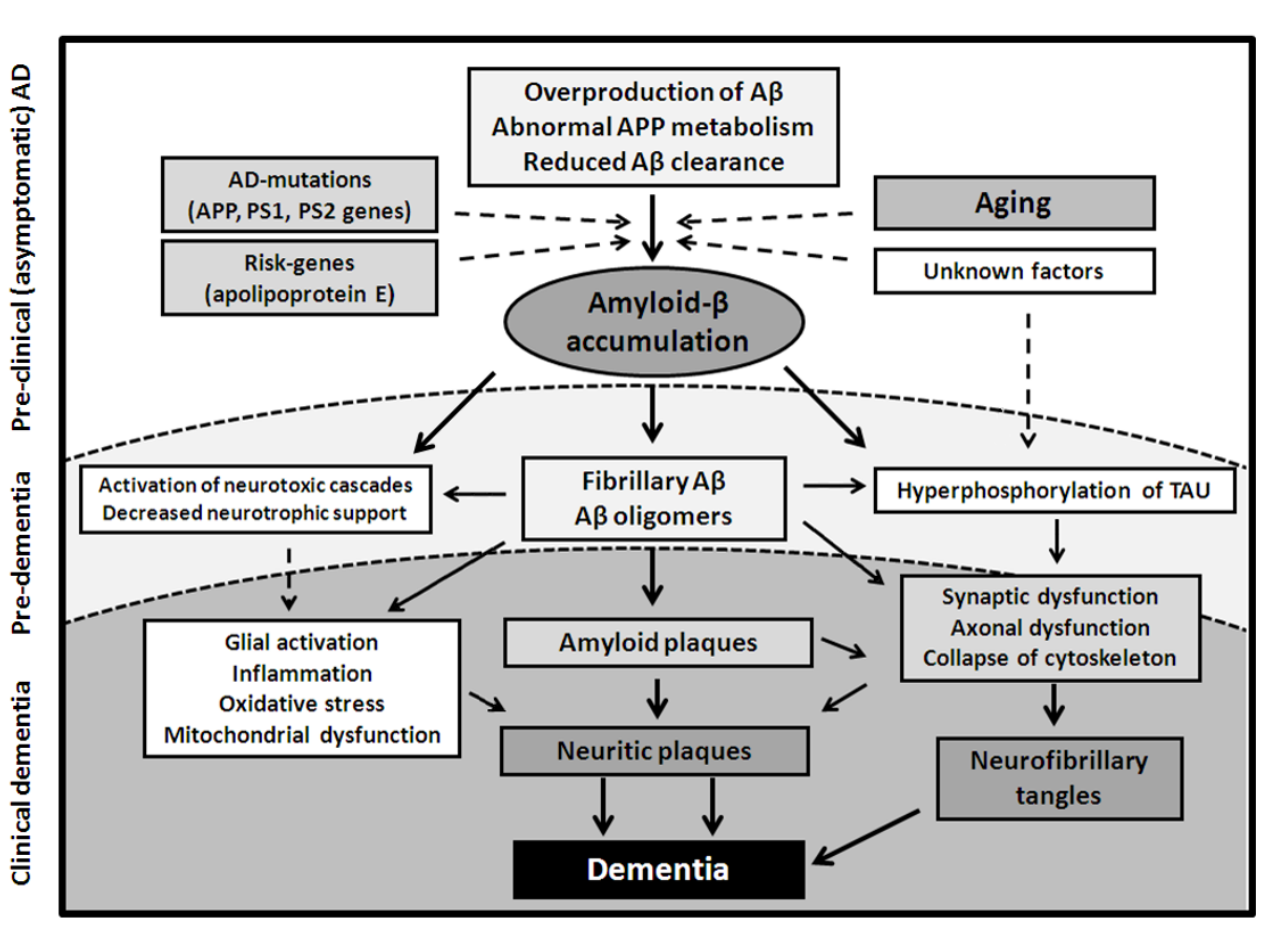

Figure 1 Hypothetical model of the pathological processes in Alzheimer's disease (AD), focusing on the amyloid $\beta$ peptide (A $\beta$ ) cascade. (Other relevant mechanisms have been omitted or presented in a secondary perspective for didactic purposes.) Dotted arrows indicate possible or secondary mechanisms affecting core pathological processes within the amyloid cascade. Background shades of gray separated by dotted lines are a schematic representation to integrate the progression of pathological events along with the development of the cognitive syndrome of $A D$ (these thresholds are arbitrary and not experimentally validated, and represent the authors' point of view of the disease process). Three clinical phases of the disease are defined: presymptomatic (or preclinical) AD may last for several years or decades until the overproduction and accumulation of $A \beta$ in the brain reaches a critical level that triggers the amyloid cascade; in the predementia phase, compatible with the definition of mild cognitive impairment secondary to $A D$, early stage pathology is present in varying degrees, from mild neuronal dystrophy to early stage Braak pathology, according to individual resilience and brain reserve. Finally, in the clinically defined dementia phase, there is a progressive accumulation of the classical pathological hallmarks of AD (that is, neuritic plaques and neurofibrillary tangles), bearing relationship with the progression of cognitive deficits and the magnitude of functional impairment. APP = amyloid precursor protein; $\mathrm{PS} 1 / 2=$ presenilin 1/2; TAU = microtubule-associated protein Tau.

the development of more specific pharmacological interventions targeting the pathological cascades of $\mathrm{AD}$.

\section{Predementia in Alzheimer's disease}

The cognitive syndrome of early stage AD is primarily represented by encoding and retrieval deficits, resulting in episodic memory impairment and diminished capacity to learn new information [17-19]. Through clinical assessment, such deficits may be revealed by memory tests such as story/picture recall and word list learning. However, the specificity of these findings may be questionable, since similar deficits can be found in other prevalent conditions in older people, namely depression and cerebrovascular disease. Studies suggest that AD-prone patients fail to benefit from associative learning strategies and from mnemonic cues (for example, cued delayed recall paradigms). In the recent literature, short-term and long-term memory binding deficits have been suggested to be strong predictors of AD in older adults [19]. These subfunctions of the memory process refer to the ability to hold multiple sources of information in memory, and to bind together different aspects of one given stimulus in order to form integrated memories. These abilities are required for associative learning, and binding deficits may be early signs of hippocampal dysfunction. In fact, AD patients have difficulties in learning associations between two or more characteristics of the same object (for example, shape and color), distinct verbal contents of one given idea, the association between faces and names, and also to integrate spatial locations to other mnemonic contents. The clinical progression towards dementia includes the additional impairment of at least one more cognitive domain, which is normally represented by executive dysfunction [20]. Recent data indicate a positive strong correlation between the magnitude of executive and functional impairment [21]. 


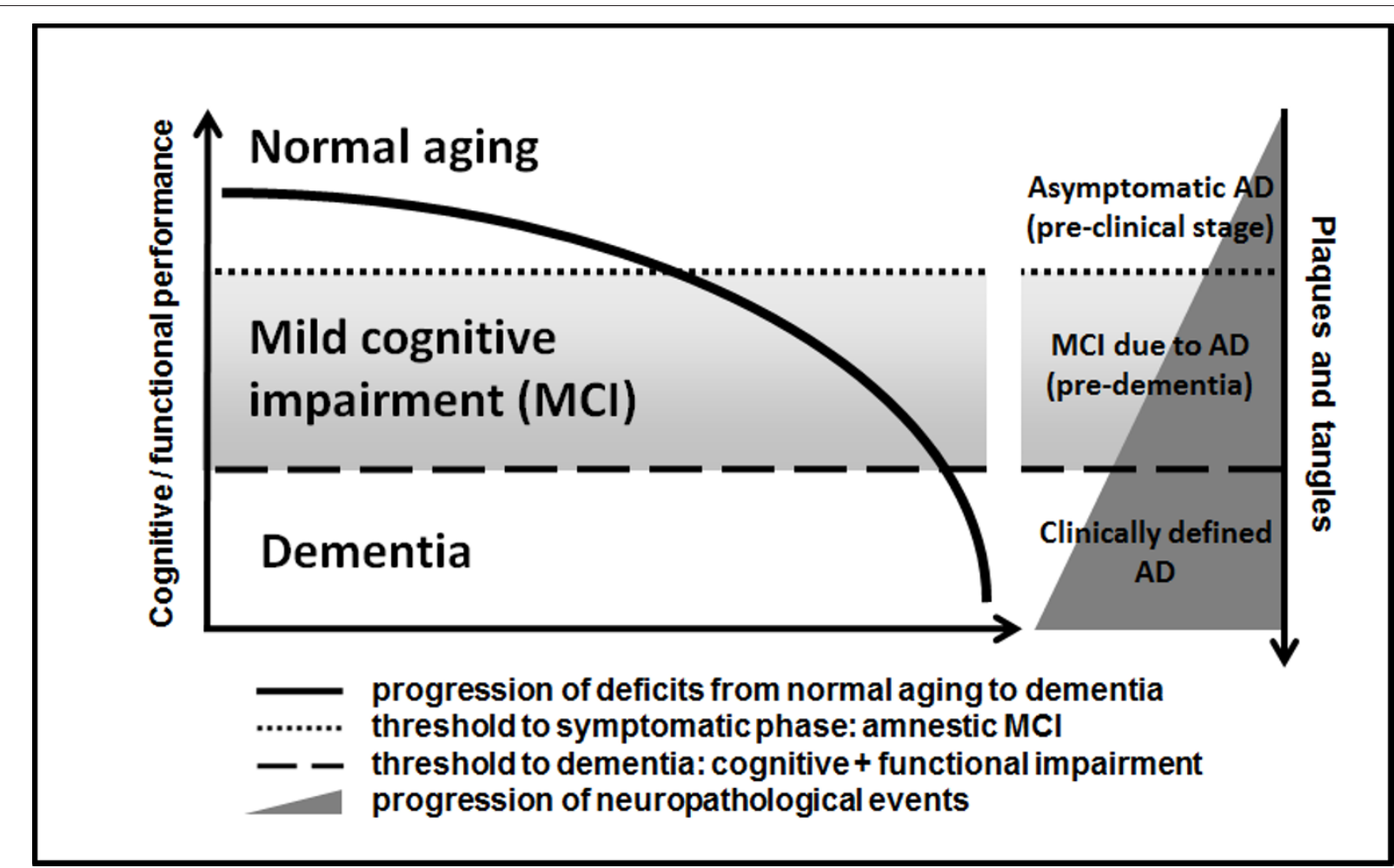

Figure 2 Relationship between the progression of cognitive and functional symptoms and the neuropathological events in the transition from asymptomatic Alzheimer's disease (AD) to mild cognitive impairment due to $A D$ and clinically manifest dementia of the $A D$ type.

The characterization of the cognitive syndrome that best predicts the AD outcome in non-demented patients has been the focus of extensive research in the past decades. However, the clinical picture of predementia AD overlaps with the cognitive changes that occur in normal ageing and other pathological processes. Frequency estimates of cognitive impairment in the older population depend critically on the definition that is adopted to yield the classification of subjects as normal or impaired. However, these different definitions not always agree with respect to the procedures that need to be adopted to rule in and out subtle cognitive deficits. In addition, the output obtained from the classification of individuals according to one given definition of cognitive impairment is highly dependent on the setting. Community samples are more heterogeneous regarding to the etiology of cognitive deficits, given the higher representation of symptoms attributed to medical and psychiatric causes. In contrast, the proportion of subjects with underlying AD pathology tends to higher in tertiary services and specialized memory clinics, where most attendees are actively seeking diagnosis and treatment for their symptoms. Therefore, the diagnosis of cognitive impairment in community samples may favor sensitivity in detriment of specificity; conversely, the positive predictive value of the diagnosis tends to be higher in patients attending memory clinics. A good illustration of this problem was published by Stephan et al. [22], who showed that the prevalence of cognitive impairment in community dwelling older adults using different definitions was as variable as $0.1 \%$ to $42 \%$. The authors concluded that the classification of individuals as cognitively impaired or normal depends critically on the way criteria are defined and operationalized. Each classification captures a unique group of individuals, with little concordance and varying prognostic value. Thus, there is an urgent need for an agreed-upon standard case definition to use as a criterion standard.

\section{Mild cognitive impairment}

Among the various definitions that have been proposed to ascertain the clinical signs and symptoms attributed to the earliest stages of dementia, the Mayo Clinic description of MCI, launched by the seminal works of Petersen and collaborators [14], is perhaps the most widely used term in the recent literature. Originally, this definition emphasized the presence of memory complaints, with objective demonstration of lower than expected performance on memory tests; there should be a global preservation of intellectual function and no 
evidence of functional impairment. A higher risk to progress to AD upon follow-up (approximately 10\% per year) was attributed to subjects diagnosed as with MCI. A few years later, the definition of MCI was broadened to encompass deficits in other cognitive domains, such as language, attention and executive functions, and also to differentiate cases with association of deficits on one, two or more cognitive domains (that is, amnestic and non-amnestic, single-domain or multiple-domain $\mathrm{MCI}$ ) $[23,24]$. Specific patterns of cognitive impairment would indicate a higher risk of distinct dementia outcomes.

Several other clinical and epidemiological investigations have also demonstrated that patients with MCI progress more often to $\mathrm{AD}$ or to other dementias than older adults without objective evidence of cognitive impairment. However, a substantial variation in the annual progression rates from MCI to AD is observed across studies, ranging from low estimates of $3 \%$ to very high estimates of $40 \%$ to $50 \%$ in samples defined according to the Mayo Clinic diagnostic criteria for MCI $[25,26]$. Several reasons have been pointed out to explain these discrepancies in conversion rates, particularly the magnitude of cognitive deficits at baseline (even though within definition limits) and the imprecise definition of functional impairment to differentiate MCI from dementia. Considering the arbitrary psychometric threshold for caseness based on the performance on cognitive tests (usually defined as 1.0 to 1.5 standard deviations below age-corrected and education-corrected population norms), the definition of MCI still accepts a relatively wide range of cognitive deficits, both in quantitative and qualitative terms. In addition, no guidelines have so far been provided to operationalize the cognitive assessment of patients (that is, which cognitive domains must be assessed in addition to memory), and which tests are more adequate for distinct populations, taking into account age-dependent, educational and cultural sources of bias [27]. Therefore, different assessment protocols to determine the degree of cognitive impairment may result in varying estimates of the cognitive deficits: more stringent tests are more sensitive to detect mild impairment of memory and other cognitive functions, whereas comprehensive batteries (for example, formal neuropsychological assessment) will more likely identify impairments in other cognitive functions beyond memory, favoring the identification of non-memory deficits and the diagnosis of multiple-domain MCI. As opposed to that, brief (function-oriented) cognitive batteries and screening tests may focus on the assessment of memory and overlook other cognitive domains. Thus, the lack of methodological uniformity to ascertain the degree and type of cognitive impairment across studies explains in part the discrepancies in prevalence and conversion rates [15].
The prognostic value of the MCI subtypes is an important issue on debate. The early definition of amnestic MCI supported the notion that the patients would present at the early stages of AD with signs of episodic memory impairment and progress linearly to a full-blown dementia syndrome. A similar assumption was attributed to other MCI subtypes and respective (theoretical) outcomes [28] (Figure 3). Nevertheless, epidemiological and clinical studies have questioned the association between MCI subtypes and specific dementia outcomes $[29,30]$. Individuals initially diagnosed as with MCI may show a long-term stability of cognitive deficits or even return to normal standards over time [31-33]. In fact, a substantial proportion of such patients may be reclassified as cognitively normal in a future evaluation. These cases are usually reported as 'unstable MCI'. It is still to be defined whether the first diagnosis was a false-positive artifact of cognitive testing, or if these individuals do recover normal cognitive function after having transient, subtle impairment. As it is, diagnostic instability is found in $5 \%$ to $20 \%$ of longitudinal samples of MCI [33]. These estimates tend to be inversely correlated with the level of certainty of raters on the clinical relevance of deficits at baseline.

Early studies assumed a linear trend between healthy cognition to MCI and dementia in older adults. These notions were based on analytical approaches that used time to event or last observation carried forward. Despite useful to determine conversion rates, these studies were not informative of the pattern of transitions between different clinical states. A different analytical strategy based on the Markov Chain model addressed the transitions between intact cognition, dementia and death in a subset of the Nun Study [34]. This model defines absorbing and non-absorbing states, which respectively represent the irreversible diagnoses of dementia (AD) or death, and the possibly reversible (or transitional) states of MCI. In this perspective, a plausible pattern of transitions between normal cognitive function, MCI and the diagnosis of AD could be: cognitively healthy subjects first develop single-domain amnestic deficits (incident $\mathrm{MCI}$ ); upon follow-up, these subjects may retain this diagnosis (in spite of the possible exacerbation of memory impairment), or eventually develop deficits in other cognitive domains in addition to memory (usually attention and/or executive dysfunction). In this case, the diagnosis of single-domain amnestic MCI is updated to multiple-domain amnestic MCI. These patients may partially recover and return to the previous classification, but most commonly they retain the multiple-domain $\mathrm{MCI}$ status until the progression of memory and non-memory (mostly dysexecutive) deficits triggers functional impairment. At this point the clinical picture becomes compatible with mild 


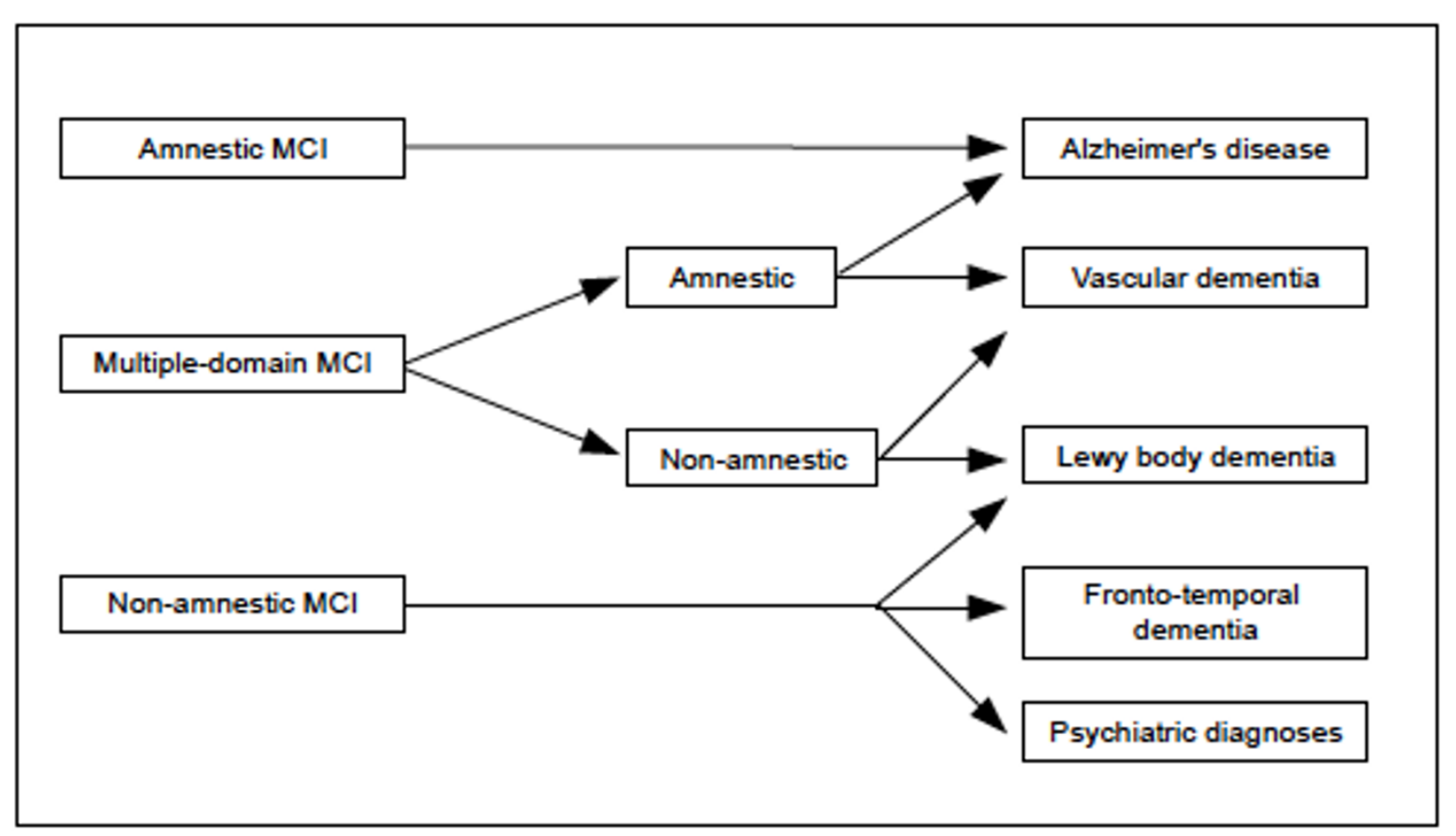

Figure 3 Hypothetical outcomes according to distinct mild cognitive impairment (MCl) subtypes [14,23].

dementia, and the diagnosis of dementia of the AD type is warranted. Reversal of deficits from this point becomes highly unlikely, which characterizes the absorbing state of dementia (AD) [20].

Therefore, the characterization of functional impairment is critical to establish the threshold between MCI and incipient dementia. Clinical and epidemiological studies have shown that patients with MCI may present subtle impairment in complex, instrumental activities of daily living (IAVDs), albeit not sufficient to impair independent living [35-38]. This is acceptable for the diagnosis of MCI according to the Mayo Clinic criteria [14]. Studies have suggested that the aggravation of functional deficits may occur independently of the worsening of memory impairment [39]. However, the magnitude of instrumental deficits to characterize conversion to dementia, given the prior diagnosis of MCI, has not been objectively defined, and this diagnosis depends primarily on clinical judgment.

This is important because the characterization of mild deficits in IAVDs in patients with MCI may hold a prognostic significance (that is, a higher risk to progress to AD/dementia). The objective evaluation of functionality has so far been neglected in the diagnostic investigation. It normally relies on the subjective report of patients and caregivers, or on the administration of functional scales to caregivers. There are several sources of bias in this form of assessment, namely the cognitive state of caregivers, the pattern of relationship between the patient and caregiver, their mood state and personality characteristics $[40,41]$. Thus, there is an urgent need for a better definition of functional impairment and for the operationalization of this assessment. In a recent study conducted in our group, the objective assessment of functional state provided evidence that patients with MCI may have mild but significant impairment in higher-order activities of daily living, such as shopping skills and managing finances, as compared to healthy older controls [42]. Functional deficits in patients with MCI and AD display a high and significant correlation with the performance on executive functions [21], and seem to be independent of age and formal schooling [43]. The magnitude of functional impairment in patients with MCI is similar among converters and non-converters, supporting the notion that mild functional impairment in also a feature of non-demented patients; however, a significant correlation between functional impairment and concentrations of phosphorylated Tau was found in the CSF of MCI patients who progressed to dementia [42], indicating that objective measures of IAVDs deficits is also correlated with well defined predictors of conversion.

As reviewed above, the concept of MCI may be sensitive to identify subjects that may develop $\mathrm{AD} /$ dementia, since most, if not all, individuals with predementia AD will present, at some point of the progression curve, with a long period of mild cognitive deficits prior to the onset of dementia. Nevertheless, as currently conceived, 
the clinically oriented diagnostic criteria for MCI yield a heterogeneous group of patients with distinct shortterm and long-term outcomes. In other words, the specificity and the predictive value of the MCI diagnosis are low, and the cross-sectional identification of cases of prodromal AD may not reach adequate diagnostic accuracy if based solely on clinical tools [15]. Rather, it benefits substantially from the combination of clinical and biological information. In the next sections we will revise the recent developments on biochemical and neuroimaging biomarkers for the early diagnosis of $\mathrm{AD}$. Of course, if such tests are unavailable, which may be the case in most healthcare settings, particularly in less favored countries, the expert interpretation of test results, the criterious observation of longitudinal measures, including the careful judgment of all available variables, is certainly the best alternative to drive clinical decisions.

\section{The search for biological biomarkers of Alzheimer's disease}

The development of biomarker research in AD is a good example of the successful effort to translate the knowledge of key pathophysiological mechanisms of the disease into clinical applications. A biomarker is a characteristic that can be measured and evaluated as an indicator of the pathogenetic processes, or to ascertain the effect of pharmacological interventions on predefined biological cascades [44]. The ideal diagnostic marker for AD should meet at least three basic requirements: (i) reflect core neurobiological changes that characterize the disease process; (ii) be validated by post mortem studies, assuming that the neuropathological findings are gold standards of abnormalities affecting the same cascade; and (iii) be measurable as early as possible in the disease continuum, ideally at presymptomatic stages. Additional requirements include being non-invasive and simple to perform, precise and reliable, and adequate for largescale screenings. Among many candidate markers, none has so far achieved universal acceptance, nor fully met the abovementioned criteria. Nonetheless, there has been significant progress toward this goal in the areas of CSF and neuroimaging biomarker identification, with attention focusing on the prediction of $\mathrm{AD}$ in the prodromal stages of disease and in high-risk groups.

\section{CSF biomarkers}

The CSF may be considered an ideal source for viable biomarkers in AD. It is in intimate contact with the cerebral tissue, and pathological changes in the brain are often reflected in the CSF [45]. Among several potential diagnostic biomarkers, the most consistent findings have been obtained with the measurement of CSF concentrations of $\mathrm{A} \beta$ peptide $\left(\mathrm{A} \beta_{42}\right)$, total Tau (T-Tau) and phosphorylated
Tau (P-Tau). AD patients characteristically display low concentrations of $\mathrm{A} \beta_{42}$ and high concentrations of T-Tau and P-Tau. This pattern of CSF biomarkers is commonly referred to as the 'AD signature' in the CSF. The aforementioned biomarkers reflect core pathophysiological features of the disease [46], and have been validated in post mortem studies [47-49]. Increased concentration of T-Tau may be a less specific marker of axonal damage, as it can be found in vascular and other neurodegenerative dementias in addition to AD (for example, prion diseases). However, it bears a positive correlation with the speed and the magnitude of the neurodegenerative process. Decreased $A \beta_{42}$ and increased P-Tau are more specific to AD. $A \beta_{42}$ is a byproduct of the abnormal processing of the amyloid precursor protein (APP) leading to amyloidogenesis and formation of neuritic plaques. In addition, decreased concentrations of $\mathrm{A} \beta_{42}$ likely reflect its deposition in plaques, preventing its clearance through the CSF P-Tau illustrates the cytoskeletal changes that arise from the deregulation of microtubule homeostasis and ultimately cause axonal dysfunction and neuronal death. This marker is more specifically associated with $\mathrm{AD}$, given the central role of Tau hyperphosphorylation in the formation of paired helical filaments (PHFs) and neurofibrillary tangles [50].

To date, over 100 studies have been published to support the notion that this AD-positive CSF pattern has good diagnostic accuracy to distinguish between normal ageing and $\mathrm{AD}(>85 \%)$ and a positive predictive value (> $90 \%)$ to determine the dementia outcome in patients with MCI [51]. However, in the differential diagnosis of established dementia syndromes, the sensitivity/specificity profile to differentiate $\mathrm{AD}$ from other dementias is significantly lower [52]. Large-scale longitudinal studies of MCI cohorts consistently demonstrated that the presence of the 'AD signature' in the CSF has a good diagnostic accuracy (that is, $>80 \%$ ) discriminating patients with $\mathrm{MCI}$ who progress to AD ('MCI converters') from those who remain cognitively stable ('MCI-stable' patients) and healthy controls [51], as well as those MCI patients who progress to non-AD dementias [53]. These sets of data have been extensively replicated by different research groups worldwide [54-57]. Findings are largely confirmatory, as reinforced by a recent meta-analysis [58]. Taken together, these studies provide compelling evidence that the 'AD signature' in the CSF is a strong predictor of dementia outcome. MCI patients who convert to AD have a CSF biomarker pattern indistinguishable to that found in patients with dementia of the AD type; and MCI patients with progressive deficits (albeit not severe enough to characterize conversion) have a similar pattern to the former patients. Conversely, MCI patients with unstable (transient) MCI and those who display non-progressive deficits over time have a CSF biomarker pattern very similar to that found in healthy older adults. 
However, a few methodological limitations need to be overcome before this knowledge can be translated into practical clinical practice. Although the determinations of CSF concentrations of these biomarkers using enzyme-linked immunosorbent assay (ELISA) or multiplex techniques (for example, xMAP; Luminex, Austin, TX, USA) have low coefficients of intralaboratory variability (5\% to $10 \%)$, the high interlaboratory variation $(20 \%$ to $30 \%$ ) is a major obstacle for the comparison of data generated in different settings. Multiple sources of bias include preassay conditions (that is, lumbar puncture protocol, sample handling and aliquot storing prior to experimentation), intra-assay conditions (different methods and protocols for the determination of the concentrations of biomarkers), and post assay variations (for example, definition of norms for patients and controls to guide the interpretation of results) [59]. This situation is a major limitation for the establishment of multicentric cooperation. The establishment of gold-standard protocols to be shared by distinct laboratories [60] and the recent launch of a multicentric quality control program with over 40 laboratories around the world will hopefully overcome these limitations in the near future.

New technologies targeting A $\beta$ oligomers in the CSF will add important insights in this field in forthcoming years. The neuropathology of AD has been linked to the accumulation of non-fibrillar forms of neurotoxic $A \beta$ oligomers. There is evidence that soluble $A \beta$ oligomers, more than amyloid fibrils per se, play a critical role triggering early pathological events of the amyloid cascade. High levels of $A \beta$ oligomers are observed in the brain and in the CSF of patients with AD, underlining their potential for the early diagnosis of the disease [61]. In a recent study using a specific method for the detection of high molecular weight $(40-200 \mathrm{kDa}) \mathrm{A} \beta$ species in the CSF, Fukumoto et al. [62] showed that the measurement of $A \beta$ oligomers might be more accurate differentiating patients with MCI and AD from normal controls, as compared to the usual methods based on fibrillar forms of the peptide. Oligomerization partially explains the lowering of $A \beta_{42}$ in the CSF of patients with $A D$, since the presence of $A \beta$ oligomers can interfere with the analyses of the peptide by conventional methods, causing underestimation of $A \beta$ levels due to epitope masking [63]. Therefore, the determination of $A \beta$ oligomers in the CSF, in addition to being useful as a diagnostic marker for $\mathrm{AD}$, can be also viewed as a potential surrogate marker for disease severity [62].

\section{Structural and functional neuroimaging}

The substantial development of neuroimaging technologies in the last decade has contributed decisively to the search for non-invasive methods to ascertain the pathological changes that evolve in the AD brain. These advances result from new protocols for the analysis of structural imaging (such as volumetric assessments of regions of interest and voxel-based morphometry based on statistical maps) [64] and functional imaging with PET, addressing the metabolic changes that presumably antedate structural damage. More recently, the investigation of $\mathrm{AD}$-specific biomarkers has been made possible with PET tracers that allow the in vivo intracerebral imaging of amyloid and Tau.

Structural changes in the brain in AD are mostly represented by global cerebral volumetric reduction, increased ventricular volumes and regional atrophy in structures of the medial temporal lobe (hippocampal formation and enthorinal cortex) [65]. Topographic gray matter loss correlates with Braak stages and may already be present in patients with very mild AD; such findings parallel the early cognitive symptoms found in the predementia phase of $\mathrm{AD}$ [8]. In comparison to $\mathrm{AD}$, patients with MCI show a relative preservation of cerebral structures; however, these patients may have mild, but significant, volumetric changes and decreased cortical thickness in specific brain regions [65-67]. Increased grey matter loss is found in converters as compared to stable MCI subjects; these patients display volumetric reductions in hippocampal and parahippocampal structures and, to a lesser extent, in the posterior cingulate cortex, middle and inferior temporal gyri, fusiform gyrus, posterior cingulate gyrus, precuneus, temporoparietal junction, and frontal cortex [68-73]. A recent metaanalysis study indicated smaller left hippocampal volumes in converter versus stable MCI patients [74].

With respect to functional neuroimaging, the main metabolic changes observed in AD are global reductions in cerebral metabolism and perfusion as shown by FDGPET and SPECT scans. These changes are observed in the temporoparietal junction, temporal, parietal and frontal lobes, hippocampal formation and posterior cingulate cortex $[75,76]$. As is the case for most methods of structural neuroimaging, patients with MCI show a pattern of changes that is intermediate between healthy older people and patients with $\mathrm{AD}[77,78]$. Likewise, in prospective studies, MCI converters show a pattern of cerebral hypometabolism that is largely similar to that found in patients with mild AD, in particular in the posterior cingulate cortex and the hippocampal regions [79-83].

The development of new technologies to visualize and quantitate $\mathrm{A} \beta$ and Tau deposits in vivo within the brain is undoubtedly a major achievement in the field AD biomarker research. The first compound to be developed for human experimentation was the 'Pittsburgh Compound $\mathrm{B}^{\prime}(\mathrm{PiB})$ [84], which is an ${ }^{11} \mathrm{C}$-labelled compound that binds intracerebral $A \beta$ in mature amyloid plaques [85]. Other compounds are the amyloid-affinity compound

${ }^{18}$ F-BAY94-9172 [86], and the dual amyloid and Tau- 
binding compound 2-(1-\{6-[(2-[18F]fluoroethyl)(methyl) amino]-2-naphthyl\}ethylidene)malononitrile (FDDNP), which has the additional property of mapping neurofibrillary tangles in addition amyloid plaques [87].

In $\mathrm{AD}$, there is an increased global cortical and regional retention of $\mathrm{PiB}$ and other compounds, particularly in the cingulate, temporal, parietal and frontal cortices [88]. Studies with amyloid imaging in mild AD have a very high sensitivity (over 90\%), but the specificity is age dependent, due to the increasing deposition of $A \beta$ over time in healthy older people. Important studies have shown negative correlations between intracerebral amyloid content (as shown by PiB scans) and CSF concentrations of $A \beta_{42}$ in patients with mild $\mathrm{AD}$ as compared to controls $[89,90]$.

As observed in other neuroimaging modalities, the PiB retention rates are also increased in patients with amnestic $\mathrm{MCI}$, albeit less than in AD patients. Positive PiB scans predict conversion, and $\mathrm{PiB}$ retention (global and regional) correlates with cognitive performance [91,92]. In a prospective study, PiB-positive MCI patients had a higher conversion rate than PiB-negative patients; in addition, the amyloid load was negatively associated with time to conversion [93]. PiB retention was also observed in older subjects without cognitive complaints or dementia; it is noteworthy that a higher retention at baseline was associated with a worse cognitive performance and predicted a faster decline [94-97]. These findings are largely compatible with the CSF biomarkers as predictors of cognitive deterioration in non-demented older adults [98]. Finally, the combination of functional and structural imaging data reinforces the notion that the accumulation of $A \beta$ in the $\mathrm{AD}$ brain precedes the onset of functional and structural changes (that is, high $\mathrm{PiB}$ retention correlates with the $\mathrm{AD}$ signature in the CSF and may be detected in the absence of significant brain atrophy [99-104]).

\section{Summary and future directions}

A well defined pattern of CSF and imaging biomarkers can be characterized in AD. These biomarkers reflect core pathological changes that evolve in the prodromal phase of $\mathrm{AD}$, including the predementia, and presumably the presymptomatic, stages of the disease. AD-related biomarkers identify with good accuracy nondemented patients with mild cognitive dysfunction who will ultimately progress to dementia, differentiating converters from healthy individuals and subjects with stable, non-progressive cognitive deficits. In addition, AD biomarkers may help to discriminate, although with lower accuracy, slow from rapid converting cases of MCI. The main biomarkers under investigation and their relationship with the pathological process in AD can be grossly subdivided into two main categories: (i) those reflecting core neuropathological changes of $\mathrm{AD}$ at the molecular level (for example, CSF biomarkers and amyloid imaging with PET), and (ii) downstream biomarkers reflecting secondary changes to brain structure and function, namely volumetric and metabolic changes to temporomedial structures (Table 1).

Table 1 Biomarkers under investigation for Alzheimer's disease

\begin{tabular}{|c|c|c|}
\hline Correlates: & Method/source: & Alzheimer's disease-related biomarkers: \\
\hline \multirow[t]{4}{*}{ Molecularcore neuropathology } & Cerebrospinal fluid & - Concentrations of amyloid $-\beta_{42}$ \\
\hline & & - Total Tau and phosphorylated Tau; \\
\hline & In vivo molecular imaging & - Intracerebral beta-amyloid load (e.g., PiB-PET, ${ }^{18}$ F-BAY94-9172); \\
\hline & & - Intracerebral aggregates of amyloid and tangle Tau(e.g., $\left.{ }^{18} \mathrm{~F}-\mathrm{FDDNP}\right) ;$ \\
\hline \multirow[t]{9}{*}{ Downstreamsecondary changes } & Structural neuroimaging(MRI) & - Regional (medial temporal) atrophy (MRI) \\
\hline & & - Volumetry of hippocampus/entorhinal cortex (MRI) \\
\hline & & - Rate of brain/regional atrophy (MRI) \\
\hline & & - Voxel-based morphometry (VBM) ${ }^{a}$ \\
\hline & & - Diffusion tensor imaging (DTI) ${ }^{a}$ \\
\hline & Functional neuroimaging(PET, SPECT, fMRI) & - Metabolic changes (FDG-PET) \\
\hline & & - Regional perfusion (SPECT) \\
\hline & & - Functional MRI $\left.\right|^{\mathrm{a}}$ and MRI perfusion-Functional connectivity ${ }^{\mathrm{a}}$ \\
\hline & Neurochemistry & - Proton spectroscopy $\left({ }^{+} \mathrm{H}-\mathrm{MRS}\right)^{\mathrm{a}}$ \\
\hline \multirow[t]{6}{*}{ Associatedhomeostatic changes } & Peripheral fluids(serum, plasma, platelets) & - Inflammatory markers (interleukins, cytokines) ${ }^{a}$ \\
\hline & & - Oxidative stress (isoprostanes) ${ }^{a}$ \\
\hline & & - $A \beta 40 / A \beta 42$ ratio*; \\
\hline & & APP ratio ${ }^{a}$ \\
\hline & & - Glycogen synthase kinase-3 $\beta$ activity $^{a}$ \\
\hline & & - Other markers of synaptic damage/neurodegeneration ${ }^{a}$ \\
\hline
\end{tabular}

${ }^{a}$ Less validated biomarkers; A , amyloid-beta peptide; APP, amyloid precursor protein; MRI, magnetic resonance imaging; MRS, magnetic resonance spectroscopy; PET, positron emission tomography; SPECT, single-photon emission tomography; FDG, fluoro-deoxyglucose; PiB, Pittsburgh Compound B; FDDNP, 2-(1-\{6-[(2-[18F] Fluoroethyl)(methyl)amino]-2-naphthyl\}ethylidene)malononitrile. 
In addition to providing biological support to the clinical diagnosis of AD, the establishment of biomarker technology has also favored the development of other important areas of research. First, the use of biomarker information can add important benefits to intervention trials, particularly with pharmaceutical compounds with disease-modifying properties. AD-positive biomarkers can be regarded as stringent inclusion criteria, defining more homogeneous samples of patients and therefore increasing the probability of success of randomized clinical trials; furthermore, the longitudinal reassessment of biomarkers can be viewed as a way to monitor specific biological outcomes of interventions with antidementia drugs, or to define proof-of-concept mechanisms of action of candidate drugs.

Secondly, given the long preclinical phase of AD, another potential use of biomarkers is the characterization of early signs of the disease in presymptomatic stages of the process. Evidence from epidemiological and autopsy studies support the hypothesis that there is a temporal lag of approximately a decade between significant accumulation of amyloid in the brain and the clinical onset of dementia. The percentage of amyloid-positive normal individuals detected at one given age closely parallels the percentage of individuals diagnosed with $\mathrm{AD}$ dementia a decade later [13]. In a longitudinal study with healthy older adults, changes in CSF biomarker levels associated with AD correlated with decline in cognitive functions, suggesting that these biomarkers may help identify early neurodegenerative processes of AD $[105,106]$. These notions have oriented recent task forces to develop diagnostic criteria for preclinical AD [107].

Finally, the actual prevention of dementia will be a tangible goal when the aforementioned challenges have been accomplished. In other words, the identification of individuals at high risk for developing dementia (including cognitively normal individuals at the presymptomatic stage of $\mathrm{AD}$ ) and the effective treatment with pharmaceutical compounds with disease modifying properties will ultimately preclude (or at least attenuate) the subsequent neurodegeneration and eventual cognitive decline (Table 2).

Table 2 Putative clinical and biological markers of the distinct stages in the AD continuum (from normal cognition to dementia), and respective therapeutic interventions (clinically supported therapies and potential interventions with candidate drugs/strategies that still require experimental validation)

\begin{tabular}{|c|c|c|c|}
\hline Clinical stage & $\begin{array}{l}\text { Underlying pathological } \\
\text { mechanisms }\end{array}$ & $\begin{array}{l}\text { Putative clinical and biological } \\
\text { markers }\end{array}$ & Potential therapeutic interventions \\
\hline \multirow[t]{3}{*}{$\begin{array}{l}\text { Asymptomatic } \\
\text { (pre-clinical AD) }\end{array}$} & $\begin{array}{l}\text { Intracerebral accumulation } \\
\text { of amyloid- } \beta\end{array}$ & - CSF concentrations of $A \beta_{42}$ & $\begin{array}{l}\text { - Cognitive reserve (education and level of intellectual } \\
\text { functioning) }\end{array}$ \\
\hline & & - Molecular imaging (PiB-PET) & $\begin{array}{l}\text { - Lifestyle changes (nutrition, physical fitness, reduction of } \\
\text { stress) }\end{array}$ \\
\hline & & $\begin{array}{l}\text { - Autossomal dominant mutation } \\
\text { (APP, PS1, PS2 genes) }\end{array}$ & $\begin{array}{l}\text { - Management of underlying factors (cardiovascular risk } \\
\text { factors, toxic and comorbid conditions) }\end{array}$ \\
\hline \multirow[t]{8}{*}{$\begin{array}{l}\text { Prodromal (pre- } \\
\text { dementia AD) }\end{array}$} & $\begin{array}{l}\text { A } \beta \text {-related pathology } \\
\text { (amyloid cascade) }\end{array}$ & $\begin{array}{l}\text { - Episodic memory impairment } \\
\text { (amnestic MCl) }\end{array}$ & $\begin{array}{l}\text { - Anti-amyloid therapy: } \\
\text { * immunotherapy anti-A } \beta \\
\text { * modulation of } \beta \text { - and } \gamma \text {-secretase } \\
\text { * anti-fibrillization agents and chelators }\end{array}$ \\
\hline & & - CSF concentrations of $A \beta_{42}$ & \\
\hline & & - Molecular imaging (PiB-PET) & \\
\hline & & $\begin{array}{l}\text { - Autossomal dominant mutation } \\
\text { (APP, PS1, PS2 genes) }\end{array}$ & \\
\hline & $\begin{array}{l}\text { Tau-related pathology } \\
\text { (neurodegeneration) }\end{array}$ & - Multiple-domain amnestic MCl & - All above \\
\hline & & $\begin{array}{l}\text { - CSF concentrations of Tau(total } \\
\text { and phosphorylated Tau) }\end{array}$ & $\begin{array}{l}\text { - Neuroprotective approaches(antioxidants, anti- } \\
\text { inflammatory drugs) }\end{array}$ \\
\hline & & - Brain metabolism (FDG-PET) & - Tau-related therapies(GSK inhibitors, lithium) \\
\hline & & $\begin{array}{l}\text { - Medial temporal lobe atrophy } \\
\text { (volumetric MRI, VBM) }\end{array}$ & - Neurorestorative approaches(NGF, BDNF, stem cells) \\
\hline \multirow[t]{4}{*}{ Clinical dementia } & $\begin{array}{c}\text { Neuritic } \\
\text { plaquesNeurofibrillary } \\
\text { tangles }\end{array}$ & - Neuropsychological tests & - Antidementia drugs (cholinesterase inhibitors, memantine) \\
\hline & & - Functional assessment & - Cognitive training \\
\hline & & - Structural imaging (CT/MRI) & - Functional rehabilitation (ADLs) \\
\hline & & - Neuropathology & - Psychoeducation (caregivers) \\
\hline
\end{tabular}

AD, Alzheimer's disease; $M C l$, mild cognitive impairment; $A \beta$, amyloid-beta peptide; CSF, cerebrospinal fluid; APP, amyloid precursor protein; $P S$, pre-senilins 1 and 2; PET, positron emission tomography; PiB, Pittsburgh compound B; FDG, fluorodeoxyglucose; CT, computerized tomography scan; MRI, magnetic resonance imaging; VBM, voxel-based morphometry. 


\section{Conclusions}

Individuals with mild cognitive deficits do display signs of AD pathology, since approximately $50 \%$ are already in Braak neurofibrillary stage III or higher, and $20 \%$ are likely to be in more advanced stages of neuropathology [108]. It is likely that those with considerable brain or cognitive reserve will be able to compensate cognitive deficits until very close to the onset of the dementia, rendering the diagnostic investigation of predementia AD based solely on cognitive measures insensitive. Therefore, the development of biomarkers for AD is needed to target the severity of underlying brain pathology independently of brain reserve.

The measurement of AD-related biomarkers in the CSF or by neuroimaging methods improves diagnostic accuracy and predictive value of the clinical classification of patients according to the definition of MCI. The characterization of early clinical signs of AD (compatible with episodic memory impairment) with the support of one or more well established biomarkers has been recently proposed as the core feature required for the diagnosis of AD in the predementia stages [109]. This supports the clinical use of definition of $\mathrm{MCI}$ in the search for cases of prodromal AD [110]. The accurate identification of subjects with underlying $\mathrm{AD}$ pathology is an acute requirement for future trials with disease-modifying drugs $[111,112]$. However, as outlined in this review, there are critical methodological problems that still need to be overcome in order to enable the translation of this robust experimental knowledge into clinical practice.

In spite of the relevant contribution of clinical and biomarker research in the early diagnosis of $\mathrm{AD}$, or even the characterization of the disease in asymptomatic or minimally symptomatic individuals, the use of these technologies raises the possibility of misidentification of cases. The incorrect classification of individuals as being at high risk for $\mathrm{AD}$ may lead to undue alarm and concern, in addition to unnecessary interventions. Therefore, before biomarker profiles are used in the general population, high specificity should be demonstrated in multiple populations. For the time being, the careful and comprehensive clinical judgment is mandatory to guide therapeutic decisions, even though the diagnostic hypothesis may be strongly reinforced by a positive biomarker. In the prospect that safe and effective, experimentally validated disease-modifying therapies become available in the near future, the reliable early detection of $\mathrm{AD}$ in the general population will become an essential tool in the prevention of this illness $[113,114]$.

\section{Acknowledgements}

The present work was supported by Conselho Nacional de Pesquisa Científica (CNPq, Project 554535/2005-0), Alzheimer's Association (NIRG-0890688), and Fundação de Amparo à Pesquisa do Estado de São Paulo
(FAPESP, Project 02/13633-7). The Laboratory of Neuroscience (LIM-27) receives financial support from Associação Beneficente Alzira Denise Hertzog da Silva (ABADHS)

\section{Authors' contributions}

The authors contributed equally to the selection and discussion of the literature reviewed in this work. The authors participated equally in the conception and preparation of the final manuscript.

\section{Competing interests}

The authors declare that they have no competing interests.

Received: 30 July 2010 Accepted: 22 December 2010

Published: 22 December 2010

\section{References}

1. Brookmeyer R, Gray S, Kawas C: Projections of Alzheimer's disease in the United States and the public health impact of delaying disease onset. Am J Public Health 1998, 88:1337-1342.

2. Brookmeyer R, Johnson E, Ziegler-Graham K, Arrighi HM: Forecasting the global burden of Alzheimer's disease. Alzheimers Dement 2007, 3:186-191.

3. Ziegler-Graham K, Brookmeyer R, Johnson E, Arrighi HM: Worldwide variation in the doubling time of Alzheimer's disease incidence rates. Alzheimers Dement 2008, 4:316-323.

4. McKhann G, Drachman D, Folstein M, Katzman R, Price D, Stadlan EM: Clinical diagnosis of Alzheimer's disease: report of the NINCDS-ADRDA Work Group under the auspices of Department of Health and Human Services Task Force on Alzheimer's Disease. Neurology 1984, 34:939-944.

5. McKhann G, Hyman B, Jack C, Kawas C, Klunk W, Knopman D, Koroshetz W, Manly J, Mayeux R, Mohs R, Morris J, Weintraub S, Alzheimer's Disease Dementia Workgroup: Criteria for AD dementia. [http://www.alz.org/ research/diagnostic_criteria/dementia_recommendations.pdf].

6. Albert M, DeKosky S, Dickson D, Dubois B, Feldman H, Fox N, Gamst A, Holtzman D, Jagust W, Petersen R, Snyder P, Mild Cognitive Impairment due to Alzheimer's Disease Workgroup: Criteria for mild cognitive impairment due to Alzheimer's disease. [http://www.alz.org/research/ diagnostic_criteria/mci_reccomendations.pdf].

7. Nelson PT, Braak H, Markesbery WR: Neuropathology and cognitive impairment in Alzheimer disease: a complex but coherent relationship. J Neuropathol Exp Neurol 2009, 68:1-14.

8. Jack CR, Knopman DS, Jagust WJ, Shaw LM, Aisen PS, Weiner MW, Petersen RC, Trojanowski JQ: Hypothetical model of dynamic biomarkers of the Alzheimer's pathological cascade. Lancet Neurol 2010, 9:119-128.

9. Blass JP: Alzheimer's disease and Alzheimer's dementia: distinct but overlapping entities. Neurobiol Aging 2002, 23:1077-1084.

10. Thal DR, Rüb U, Schultz C, Sassin I, Ghebremedhin E, Del Tredici K, Braak E, Braak $\mathrm{H}$ : Sequence of $A \beta$-protein deposition in the human medial temporal lobe. J Neuropathol Exp Neurol 2000, 59:733-748.

11. Thal DR, Rüb U, Orantes $M$, Braak $H$ : Phases of $A$ B-deposition in the human brain and its relevance for the development of AD. Neurology 2002, 58:1791-1800.

12. Knopman DS, Parisi JE, Salviati A, Floriach-Robert M, Boeve BF, Ivnik RJ, Smith GE, Dickson DW, Johnson KA, Petersen LE, McDonald WC, Braak H, Petersen RC: Neuropathology of cognitively normal elderly. I Neuropathol Exp Neurol 2003, 62:1087-1095.

13. Morris JC, Roe CM, Grant EA, Head D, Storandt M, Goate AM, Fagan AM, Holtzman DM, Mintun MA: Pittsburgh compound B imaging and prediction of progression from cognitive normality to symptomatic Alzheimer disease. Arch Neurol 2009, 66:1469-1475.

14. Petersen RC, Smith GE, Waring SC, Ivnik RJ, Tangalos EG, Kokmen E: Mild cognitive impairment: clinical characterization and outcome. Arch Neurol 1999, 56:303-308.

15. Forlenza OV, Chiu E: Mild cognitive impairment: a concept ready to move on? Cur Opin Psychiatry 2008, 21:529-532.

16. Petersen RC, Parisi JE, Dickson DW, Johnson KA, Knopman DS, Boeve BF, Jicha GA, Ivnik RJ, Smith GE, Tangalos EG, Braak H, Kokmen E: Neuropathologic features of amnestic mild cognitive impairment. Arch Neurol 2006, 63:665-672.

17. Small BJ, Fratiglioni L, Viitanen M, Winblad B, Bäckman L: The course of cognitive impairment in preclinical Alzheimer disease: three- and 6-year follow-up of a population-based sample. Arch Neurol 2000, 57:839-844. 
18. Blacker D, Lee H, Muzikansky A, Martin EC, Tanzi R, McArdle JJ, Moss M, Albert M: Neuropsychological measures in normal individuals that predict subsequent cognitive decline. Arch Neurol 2007, 64:862-871.

19. Parra MA, Abrahams S, Fabi K, Logie R, Luzzi S, Della Sala S: Short term memory binding deficits in Alzheimer's disease. Brain 2009, 132:1057-1066.

20. Forlenza OV, Diniz BS, Nunes PV, Memoria CM, Yassuda MS, Gattaz WF: Diagnostic transitions in mild cognitive impairment subtypes. Int Psychogeriatr 2009, 21:1088-1095.

21. Pereira FS, Yassuda MS, Oliveira AM, Forlenza OV: Executive dysfunction correlates with impaired functional status in older adults with varying degrees of cognitive impairment. Int Psychogeriatr 2008, 20:1104-1115.

22. Stephan BC, Matthews FE, McKeith IG, Bond J, Brayne C, Medical Research Council Cognitive Function and Aging Study: Early cognitive change in the general population: how do different definitions work? J Am Geriatr Soc 2007, 55:1534-1540.

23. Petersen RC, Stevens JC, Ganguli M, Tangalos EG, Cummings JL, DeKosky ST: Practice parameter: early detection of dementia: mild cognitive impairment (an evidence-based review). Report of the Quality Standards Subcommittee of the American Academy of Neurology. Neurology 2001, 56:1133-1142.

24. Winblad B, Palmer K, Kivipelto M, Jelic V, Fratiglioni L, Wahlund LO, Nordberg A, Bäckman L, Albert M, Almkvist O, Arai H, Basun H, Blennow K, de Leon M, DeCarli C, Erkinjuntti T, Giacobini E, Graff C, Hardy J, Jack C, Jorm A, Ritchie K, van Duijn C, Visser P, Petersen RC: Mild cognitive impairment-beyond controversies, towards a consensus: report of the International Working Group on Mild Cognitive Impairment. J Intern Med 2004, 256:240-246

25. Bruscoli $\mathrm{M}$, Lovestone $\mathrm{S}$ : Is $\mathrm{MCl}$ really just early dementia? A systematic review of conversion studies. Int Psychogeriatr 2004, 16:129-140.

26. Mitchell A, Shiri-Feshki M: Rate of progression of mild cognitive impairment to dementia - meta-analysis of 41 robust inception cohort studies. Acta Psychiatr Scand 2009, 119:252-265.

27. Visser $P$, Scheltens $P$, Verhey FR: Do $M C l$ criteria in drug trials accurately identify subjects with predementia Alzheimer's disease? J Neurol Neurosurg Psychiatry 2005, 76:1348-1354.

28. Petersen RC: Mild cognitive impairment as a diagnostic entity. J Intern Med 2004, 256:183-194

29. Busse A, Hansel A, Gühne U, Angermeyer MC, Riedel-Heller SG: Mild cognitive impairment: long-term course of four clinical subtypes. Neurology 2006, 67:2176-2185.

30. Fischer $P$, Jungwirth $S$, Zehetmayer $S$, Weiss-gram S, Hoenigschnabl S, Gelpi E, Krampla W, Tragl KH: Conversion of subtypes of mild cognitive impairment to Alzheimer dementia. Neurology 2007, 68:288-291.

31. Palmer K, Wang HX, Bäckman L, Winblad B, Fratiglioni L: Differential evolution of cognitive impairment in nondemented older persons: results from the Kungsholmen project. Am J Psychiatry 2002, 159:436-442.

32. Loewenstein DA, Acevedo A, Agron J, Duara R: Stability of neurocognitive impairment in different subtypes of mild cognitive impairment. Dement Geriatr Cogn Disord 2007, 23:82-86.

33. Diniz BS, Nunes PV, Yassuda MS, Forlenza O: Diagnosis of mild cognitive impairment revisited after one year. Preliminary results of a prospective study. Dement Geriatr Cogn Disord 2009, 27:224-231.

34. Tyas SL, Salazar JC, Snowdon DA, Desrosiers MF, Riley KP, Mendiondo MS, Kryscio RJ: Transitions to mild cognitive impairments, dementia, and death: findings from the Nun Study. Am J Epidemio/ 2007, 165:1231-1238.

35. Burton CL, Strauss E, Bunce D, Hunter MA, Hultsch DF: Functional abilities in older adults with mild cognitive impairment. Gerontology 2009, 55:570-581.

36. Kim KR, Lee KS, Cheong HK, Eom JS, Oh BH, Hong CH: Characteristic profiles of instrumental activities of daily living in different subtypes of mild cognitive impairment. Dement Geriatr Cogn Disord 2009, 27:278-285.

37. Wadley VG, Okonkwo O, Crowe M, Ross-Meadows LA: Mild cognitive impairment and everyday function: evidence of reduced speed in performing instrumental activities of daily living. Am J Geriatr Psychiatry 2008, 16:416-424.

38. Jefferson AL, Byerly LK, Vanderhill S, Lambe S, Wong S, Ozonoff A, Karlawish $\mathrm{JH}$ : Characterization of activities of daily living in individuals with mild cognitive impairment. Am J Geriatr Psychiatry 2008, 16:375-383.

39. Rozzini L, Chilovi BV, Conti M, Bertoletti E, Delrio I, Trabucchi M, Padovani A: Conversion of amnestic mild cognitive impairment to dementia of
Alzheimer type is independent to memory deterioration. Int J Geriatr Psychiatry 2007, 22:1217-1222.

40. Jorm AF: Assessment of cognitive impairment and dementia using informant report. Clin Psychol Rev 1996, 16:51-73.

41. Abreu ID, Nunes PV, Diniz BS, Forlenza OV: Combining functional scales and cognitive tests in screening for mild cognitive impairment at a university-based memory clinic in Brazil. Rev Bras Psiquiatr 2008, 30:346-349.

42. Pereira FS, Yassuda MS, Oliveira AM, Diniz BS, Radanovic M, Talib LL, Gattaz WF, Forlenza OV: Profiles of functional deficits in mild cognitive impairment and dementia: benefits from objective measurement. J Int Neuropsychol Soc 2010, 16:297-305.

43. Pereira FS, Oliveira AM, Diniz BS, Forlenza OV, Yassuda MS: Cross-cultural adaptation, reliability and validity of the DAFS-R in a sample of Brazilian older adults. Arch Clin Neuropsychol 2010, 25:335-343.

44. Wagner JA: Biomarkers: principles, policies, and practice. Clin Pharmacol Ther 2009, 86:3-7.

45. Reiber H: Dynamics of brain-derived proteins in cerebrospinal fluid. Clin Chim Acta 2001, 310:173-186.

46. Wiltfang J, Lewczuk $P$, Riederer $P$, Grünblatt $E$, Hock $C$, Scheltens $P$, Hampel H, Vanderstichele H, lqbal K, Galasko D, Lannfelt L, Otto M, Esselmann H, Henkel AW, Kornhuber J, Blennow K: Consensus paper of the WFSBP Task Force on Biological Markers of Dementia: the role of CSF and blood analysis in the early and differential diagnosis of dementia. World J Biol Psychiatry 2005, 6:69-84.

47. Buerger K, Ewers M, Pirttilä T, Zinkowski R, Alafuzoff I, Teipel SJ, DeBernardis J, Kerkman D, McCulloch C, Soininen H, Hampel H: CSF phosphorylated tau protein correlates with neocortical neurofibrillary pathology in Alzheimer's disease. Brain 2006, 129:3035-3041.

48. Clark CM, Xie S, Chittams J, Ewbank D, Peskind E, Galasko D, Morris JC McKeel DW Jr, Farlow M, Weitlauf SL, Quinn J, Kaye J, Knopman D, Arai H, Doody RS, DeCarli C, Leight S, Lee VM, Trojanowski JQ: Cerebrospinal fluid tau and beta-amyloid: how well do these biomarkers reflect autopsyconfirmed dementia diagnoses? Arch Neurol 2003, 60:1696-1702.

49. Tapiola T, Alafuzoff I, Herukka SK, Parkkinen L, Hartikainen P, Soininen H, Pirttilä T: Cerebrospinal fluid $\beta$-amyloid 42 and tau proteins as biomarkers of Alzheimer-type pathologic changes in the brain. Arch Neurol 2009, 66:382-389.

50. Blennow K, Hampel H: CSF markers for incipient Alzheimer's disease. Lancet Neurol 2003, 2:605-613.

51. Hansson O, Zetterberg H, Buchhave P, Londos E, Blennow K, Minthon L: Association between CSF biomarkers and incipient Alzheimer's disease in patients with mild cognitive impairment: a follow-up study. Lancet Neurol 2006, 5:228-34.

52. Andreasen N, Minthon L, Davidsson $P$, Vanmechelen $E$, Vanderstichele $H$ Winblad B, Blennow K: Evaluation of CSF-tau and CSF-A 342 as diagnostic markers for Alzheimer disease in clinical practice. Arch Neurol 2001, 58:373-379.

53. Riemenschneider M, Lautenschlager N, Wagenpfeil S, Diehl J, Drzezga A, Kurz A: Cerebrospinal fluid tau and $\beta$-amyloid 42 proteins identify Alzheimer disease in subjects with mild cognitive impairment. Arch Neurol 2002, 59:1729-1734.

54. Arai $H$, Ishiguro $K$, Ohno H, Moriyama M, Itoh N, Okamura N, Matsui T, Morikawa Y, Horikawa E, Kohno H, Sasaki H, Imahori K: CSF phosphorylated tau protein and mild cognitive impairment: a prospective study. Exp Neurol 2000, 166:201-203

55. Hampel H, Teipel SJ, Fuchsberger T, Andreasen N, Wiltfang J, Otto M, Shen Y, Dodel R, Du Y, Farlow M, Möller HJ, Blennow K, Buerger K: Value of CSF beta-amyloid1-42 and tau as predictors of Alzheimer's disease in patients with mild cognitive impairment. Mol Psychiatry 2004, 9:705-710.

56. Shaw LM, Vanderstichele H, Knapik-Czajka M, Clark CM, Aisen PS, Petersen RC, Blennow K, Soares H, Simon A, Lewczuk P, Dean R, Siemers E, Potter W, Lee VM, Trojanowski JQ, Alzheimer's Disease Neuroimaging Initiative: Cerebrospinal fluid biomarker signature in Alzheimer's disease neuroimaging initiative subjects. Ann Neurol 2009, 65:403-413.

57. Forlenza OV, Diniz BS, Talib LL, Radanovic M, Yassuda MS, Ojopi EB, Gattaz WF: Clinical and biological predictors of Alzheimer's disease in patients with amnestic mild cognitive impairment. Rev Bras Psiquiatr 2010, 32:216-222.

58. Diniz B, Pinto J, Forlenza OV: Do CSF total tau, phosphorylated tau, and $\beta$-amyloid 42 help to predict progression of mild cognitive impairment 
to Alzheimer's disease? A systematic review and meta-analysis of the literature. World J Biol Psychiatry 2008, 9:172-182.

59. Mattsson $\mathrm{N}$, Blennow $\mathrm{K}$, Zetterberg $\mathrm{H}$ : Inter-laboratory variation in cerebrospinal fluid biomarkers for Alzheimer's disease: united we stand, divided we fall. Clin Chem lab Med 2010, 48:603-607.

60. Blennow $\mathrm{K}$, Hampel H, Weiner M, Zetterberg $\mathrm{H}$ : Cerebrospinal fluid and plasma biomarkers in Alzheimer disease. Nat Rev Neurol 2010, 6:131-144.

61. Santos AN, Torkler S, Nowak D, Schlittig C, Goerdes M, Lauber T, Trischmann L, Schaupp M, Penz M, Tiller FW, Böhm G: Detection of amyloid- $\beta$ oligomers in human cerebrospinal fluid by flow cytometry and fluorescence resonance energy transfer. J Alzheimers Dis 2007, 11:117-125.

62. Fukumoto $H$, Tokuda $T$, Kasai T, Ishigami N, Hidaka H, Kondo M, Allsop D, Nakagawa M: High-molecular-weight $\beta$-amyloid oligomers are elevated in cerebrospinal fluid of Alzheimer patients. FASEB J 2010, 24:2716-2726.

63. Englund H, Degerman Gunnarsson M, Brundin RM, Hedlund M, Kilander L, Lannfelt L, Pettersson FE: Oligomerization partially explains the lowering of A 442 in Alzheimer's disease cerebrospinal fluid. Neurodegener Dis 2009, 6:139-147

64. Busatto GF, Diniz BS, Zanetti MV: Voxel-based morphometry in Alzheimer's disease. Expert Rev Neurother 2008, 8:1691-1702.

65. Apostolova LG, Dinov ID, Dutton RA, Hayashi KM, Toga AW, Cummings JL, Thompson PM: 3D comparison of hippocampal atrophy in amnestic mild cognitive impairment and Alzheimer's disease. Brain 2006, 129:2867-2873.

66. Seo SW, Im K, Lee JM, Kim YH, Kim ST, Kim SY, Yang DW, Kim SI, Cho YS, $\mathrm{Na} \mathrm{DL}$ : Cortical thickness in single-versus multiple-domain amnestic mild cognitive impairment. Neurolmage 2007, 36:289-297.

67. Singh V, Chertkow H, Lerch JP, Evans AC, Dorr AE, Kabani NJ: Spatial patterns of cortical thinning in mild cognitive impairment and Alzheimer's disease. Brain 2006, 129:2885-2893.

68. Davatzikos C, Xu F, An Y, Fan Y, Resnick SM: Longitudinal progression of Alzheimer's-like patterns of atrophy in normal older adults: the SPAREAD index. Brain 2009, 132:2026-2035.

69. Chetelat G, Desgranges B, de la Sayette V, Viader F, Eustache F, Baron JC, Mild cognitive impairment: Can FDG-PET predict who is to rapidly convert to Alzheimer's disease? Neurology 2003, 60:1374-1377.

70. Chetelat G, Eustache F, Viader F, De La Sayette V, Pölerin A, Mäzenge F, Hannequin D, Dupuy B, Baron JC, Desgranges B: FDG-PET measurement is more accurate than neuropsychological assessments to predict global cognitive deterioration in patients with mild cognitive impairment. Neurocase 2005, 11:14-25

71. Tapiola T, Pennanen C, Tapiola M, Tervo S, Kivipelto M, Hänninen T, Pihlajamäki M, Laakso MP, Hallikainen M, Hämäläinen A, Vanhanen M, Helkala EL, Vanninen R, Nissinen A, Rossi R, Frisoni GB, Soininen H: MRI of hippocampus and entorhinal cortex in mild cognitive impairment: a follow-up study. Neurobiol Aging 2008, 29:31-38.

72. Hämäläinen A, Tervo S, Grau-Olivares M, Niskanen E, Pennanen C, Huuskonen J, Kivipelto M, Hänninen T, Tapiola M, Vanhanen M, Hallikainen M, Helkala EL, Nissinen A, Vanninen R, Soininen H: Voxel-based morphometry to detect brain atrophy in progressive mild cognitive impairment. Neurolmage 2007, 37:1122-1131.

73. Ridha BH, Barnes J, Bartlett JW, Godbolt A, Pepple T, Rossor MN, Fox NC: Tracking atrophy progression in familial Alzheimer's disease: a serial MRI study. Lancet Neurol 2006, 5:828-834.

74. Ferreira LK, Diniz BS, Forlenza OV, Busatto GF, Zanetti MV: Neurostructural predictors of Alzheimer's disease: a meta-analysis of VBM studies. Neurobiol Aging

75. Mielke R, Pietrzyk U, Jacobs A, Fink GR, Ichimiya A, Kessler J, Herholz K, Heiss WD: HMPAO SPET and FDG PET in Alzheimer's disease and vascular dementia: comparison of perfusion and metabolic pattern. Eur $J$ Nucl Med 1994, 21:1052-1060.

76. Herholz K, Salmon E, Perani D, Baron JC, Holthoff V, Frölich L, Schönknecht P, Ito K, Mielke R, Kalbe E, Zändorf G, Delbeuck X, Pelati O, Anchisi D, Fazio F, Kerrouche N, Desgranges B, Eustache F, BeuthienBaumann B, Menzel C, Schröder J, Kato T, Arahata Y, Henze M, Heiss WD: Discrimination between Alzheimer dementia and controls by automated analysis of multicenter FDG PET. Neuroimage 2002, 17:302-316.

77. Nobili F, Salmaso D, Morbelli S, Girtler N, Piccardo A, Brugnolo A, Dessi B, Larsson SA, Rodriguez G, Pagani M: Principal component analysis of FDG PET in amnestic MCl. Eur J Nucl Med Mol Imaging 2008, 35:2191-2202.
78. Mosconi L, Tsui WH, Herholz K, Pupi A, Drzezga A, Lucignani G, Reiman EM, Holthoff V, Kalbe E, Sorbi S, Diehl-Schmid J, Perneczky R, Clerici F, Caselli R, Beuthien-Baumann B, Kurz A, Minoshima S, de Leon MJ: Multicenter standardized 18F-FDG PET diagnosis of mild cognitive impairment, Alzheimer's disease, and other dementias. J Nucl Med 2008, 49:390-398.

79. Chetelat G, Desgranges B, de la Sayette V, Viader F, Eustache F, Baron JC: Mild cognitive impairment: Can FDG-PET predict who is to rapidly convert to Alzheimer's disease? Neurology 2003, 60:1374-1377.

80. Chetelat G, Landeau B, Eustache F, Mezenge F, Viader F, de la Sayette V, Desgranges $B$, Baron JC: Using voxel-based morphometry to map the structural changes associated with rapid conversion in MCl: a longitudinal MRI study. Neurolmage 2005, 27:934-946.

81. Mosconi L, Perani D, Sorbi S, Herholz K, Nacmias B, Holthoff V, Salmon E, Baron JC, De Cristofaro MT, Padovani A, Borroni B, Franceschi M, Bracco L, Pupi A: $\mathrm{MCl}$ conversion to dementia and the APOE genotype: a prediction study with FDG-PET. Neurology 2004, 63:2332-2340.

82. DeLeon MJ, Convit A, Wolf OT, Tarshish CY, DeSanti S, Rusinek H, Tsui W, Kandil E, Scherer AJ, Roche A, Imossi A, Thorn E, Bobinski M, Caraos C, Lesbre P, Schlyer D, Poirier J, Reisberg B, Fowler J: Prediction of cognitive decline in normal elderly subjects with 2-[(18)F]fluoro-2-deoxy-dglucose/poitron-emission tomography (FDG/PET). Proc Natl Acad Sci USA 2001, 98:10966-10971.

83. Drzezga A, Grimmer T, Riemenschneider M, Lautenschlager $\mathrm{N}$, Siebner $\mathrm{H}$, Alexopoulus P, Minoshima S, Schwaiger M, Kurz A: Prediction of individual clinical outcome in MCl by means of genetic assessment and (18)F-FDG PET. J NuCl Med 2005, 46:1625-1632.

84. Mathis C, Wang Y, Holt DP, Huang GF, Debnath ML, Klunk W: Synthesis and evaluation of 11C-labeled 6-substituted 2-arylbenzothiazoles as amyloid imaging agents. J Med Chem 2003, 46:2740-2754.

85. Klunk WE, Engler H, Nordberg A, Wang Y, Blomqvist G, Holt DP, Bergström M, Savitcheva I, Huang GF, Estrada S, Ausén B, Debnath ML, Barletta J, Price JC, Sandell J, Lopresti BJ, Wall A, Koivisto P, Antoni G, Mathis CA, Långström B: Imaging brain amyloid in Alzheimer's disease with Pittsburgh Compound-B. Ann Neurol 2004, 55:306-319.

86. Rowe CC, Ackerman U, Browne W, Mulligan R, Pike KL, O'Keefe G, TochonDanguy H, Chan G, Berlangieri SU, Jones G, Dickinson-Rowe KL, Kung HP, Zhang W, Kung MP, Skovronsky D, Dyrks T, Holl G, Krause S, Friebe M, Lehman $L$, Lindemann $S$, Dinkelborg LM, Masters CL, Villemagne VL: Imaging of amyloid $\beta$ in Alzheimer's disease with 18F-BAY94-9172, a novel PET tracer: proof of mechanism. Lancet Neurol 2008, 7:129-135.

87. Small GW, Kepe V, Ercoli LM, Siddarth P, Bookheimer SY, Miller KJ Lavretsky H, Burggren AC, Cole GM, Vinters HV, Thompson PM, Huang SC, Satyamurthy N, Phelps ME, Barrio JR: PET of brain amyloid and tau in mild cognitive impairment. New Engl J Med 2006, 355:2652-2663.

88. Edison P, Archer HA, Hinz R, Hammers A, Pavese N, Tai YF, Hotton G, Cutler D, Fox N, Kennedy A, Rossor M, Brooks DJ: Amyloid, hypometabolism, and cognition in Alzheimer disease: an [11C]PIB and [18F]FDG PET study. Neurology 2007, 68:501-508.

89. Fagan AM, Mintun MA, Mach RH, Lee SY, Dence CS, Shah AR, LaRossa GN, Spinner ML, Klunk WE, Mathis CA, DeKosky ST, Morris JC, Holtzman DM: Inverse relation between in vivo amyloid imaging load and cerebrospinal fluid A $A 42$ in humans. Ann Neurol 2006, 59:512-519.

90. Fagan AM, Mintun MA, Shah AR, Aldea P, Roe CM, Mach RH, Marcus D, Morris JC, Holtzman DM: Cerebrospinal fluid tau and ptau(181) increase with cortical amyloid deposition in cognitively normal individuals: implications for future clinical trials of Alzheimer's disease. EMBO Mol Med 2009, 1:371-380.

91. Kemppainen NM, Aalto S, Wilson IA, Någren K, Helin S, Brück A, Oikonen V, Kailajärvi M, Scheinin M, Viitanen M, Parkkola R, Rinne JO: PET amyloid ligand [11C]PIB uptake is increased in mild cognitive impairment. Neurology 2007, 68:1603-1606.

92. Forsberg A, Engler H, Almkvist O, Blomquist G, Hagman G, Wall A, Ringheim A, Langström B, Nordberg A: PET imaging of amyloid deposition in patients with mild cognitive impairment. Neurobiol Aging 2008, 29:1456-1465.

93. Okello A, Koivunen J, Edison P, Archer HA, Turkheimer FE, Nagren K, Bullock R, Walker Z, Kennedy A, Fox NC, Rossor MN, Rinne JO, Brooks DJ: Conversion of amyloid positive and negative $\mathrm{MCl}$ to $\mathrm{AD}$ over 3 years: an 11C-PIB PET study. Neurology 2009, 73:754-760.

94. Villemagne V, Pike KE, Darby D, Maruff P, Savage G, Ng S, Ackermann U, Cowie TF, Currie J, Chan SG, Jones G, Tochon-Danguy H, O'Keefe G, 
Masters $C L$, Rowe $C C$ : $A \beta$ deposits in older non-demented individuals with cognitive decline are indicative of preclinical Alzheimer's disease. Neuropsychologia 2008, 46:1688-1697.

95. Aizenstein HJ, Nebes RD, Saxton JA, Price JC, Mathis CA, Tsopelas ND, Ziolko SK, James JA, Snitz BE, Houck PR, Bi W, Cohen AD, Lopresti BJ, DeKosky ST, Halligan EM, Klunk WE: Frequent amyloid deposition without significant cognitive impairment among the elderly. Arch Neurol 2008, 65:1509-1517.

96. Resnick SM, Sojkova J, Zhou Y, An Y, Ye W, Holt DP, Dannals RF, Mathis CA, Klunk WE, Ferrucci L, Kraut MA, Wong DF: Longitudinal cognitive decline is associated with fibrillar amyloid- $\beta$ measured by [11C]PiB. Neurology 2010, 74:807-815.

97. Reiman EM, Chen K, Liu X, Bandy D, Yu M, Lee W, Ayutyanont N, Keppler J, Reeder SA, Langbaum JB, Alexander GE, Klunk WE, Mathis CA, Price JC, Aizenstein HJ, DeKosky ST, Caselli RJ: Fibrillar amyloid- $\beta$ burden in cognitively normal people at 3 levels of genetic risk for Alzheimer's disease. Proc Natl Acad Sci USA 2009, 106:6820-6825.

98. Fagan A, Roe CM, Xiong C, Mintun MA, Morris J, Holtzman D: Cerebrospinal fluid tau/ $\beta$-amyloid(42) ratio as a prediction of cognitive decline in nondemented older adults. Arch Neurol 2007, 64:343-349.

99. Fellgiebel A, Siessmeier T, Scheurich A, Winterer G, Bartenstein P, Schmidt LG, Möller MJ: Association of elevated phospho-tau levels with Alzheimer-typical 18F-fluoro-2-deoxy-D-glucose positron emission tomography findings in patients with mild cognitive impairment. Biol Psychiatry 2004, 56:279-283.

100. Bouwman FH, Schoonenboom SN, van der Flier WM, van Elk EJ, Kok A, Barkhof F, Blankenstein MA, Scheltens P: CSF biomarkers and medial temporal lobe atrophy predict dementia in mild cognitive impairment. Neurobiol Aging 2007, 28:1070-1074.

101. Josephs KA, Whitwell JL, Ahmed Z, Shiung MM, Weigand SD, Knopman DS, Boeve BF, Parisi JE, Petersen RC, Dickson DW, Jack CR Jr: Beta-amyloid burden is not associated with rates of brain atrophy. Ann Neurol 2008, 63:204-212.

102. Hansson O, Buchhave P, Zetterberg H, Blennow K, Minthon L, Warkentin S: Combined rCBF and CSF biomarkers predict progression from mild cognitive impairment to Alzheimer's disease. Neurobiol Aging 2009, 30:165-173.

103. J Jack CR Jr, Lowe VJ, Weigand SD, Wiste HJ, Senjem ML, Knopman DS, Shiung MM, Gunter JL, Boeve BF, Kemp BJ, Weiner M, Petersen RC, the Alzheimer's Disease Neuroimaging Initiative: Serial PIB and MRI in normal, mild cognitive impairment and Alzheimer's disease: implications for sequence of pathological events in Alzheimer's disease. Brain 2009, 132:1355-1365.

104. Walhovd KB, Fjell AM, Brewer J, McEvoy LK, Fennema-Notestine C, Hagler DJ, Jennings RG, Karow D, Dale AM, the Alzheimer's Disease Neuroimaging Initiative: Combining MR imaging, positron-emission tomography, and CSF biomarkers in the diagnosis and prognosis of Alzheimer disease. Am J Neuroradiol 2010, 31:347-354.

105. Stomrud E, Hansson O, Blennow K, Minthon L, Londos E: Cerebrospinal fluid biomarkers predict decline in subjective cognitive function over 3 years in healthy elderly. Dement Geriatr Cogn Disord 2007, 24:118-124.

106. Stomrud E, Hansson O, Zetterberg H, Blennow K, Minthon L, Londos E: Correlation of longitudinal cerebrospinal fluid biomarkers with cognitive decline in healthy older adults. Arch Neurol 2010, 67:217-223.

107. Sperling R, Beckett L, Bennett D, Craft S, Fagan A, Kaye J, Montine T, Park D, Reiman E, Siemers E, Stern Y, Yaffe K, Preclinical Alzheimer's Disease Workgroup: Criteria for preclinical Alzheimer's disease.[http://www.alz.org/ research/diagnostic_criteria/preclinical_recommendations.pdf].

108. Riley KP, Snowdon DA, Markesbery WR: Alzheimer's neurofibrillary pathology and the spectrum of cognitive function: findings from the Nun Study. Ann Neurol 2002, 51:567-577.

109. Dubois B, Feldman HH, Jacova C, Dekosky ST, Barberger-Gateau P, Cummings J, Delacourte A, Galasko D, Gauthier S, Jicha G, Meguro K, O'Brien J, Pasquier F, Robert P, Rossor M, Salloway S, Stern Y, Visser PJ, Scheltens P: Research criteria for the diagnosis of Alzheimer's disease: revising the NINCDS-ADRDA criteria. Lancet Neurol 2007, 6:734-746.

110. Petersen RC, Knopman DS: MCl is a clinically useful concept. Int Psychogeriatr 2006, 18:394-314.

111. Citron M: Alzheimer's disease: strategies for disease modification. Nat Rev Drug Discov 2010, 9:387-398.
112. Frank RA, Galasko D, Hampel H, Hardy J, de Leon MJ, Mehta PD, Rogers J, Siemers E, Trojanowski JQ, National Institute on Aging Biological Markers Working G: Biological markers for therapeutic trials in Alzheimer's disease. Proceedings of the biological markers working group; NIA initiative on neuroimaging in Alzheimer's disease. Neurobiol Aging 2003, 24:521-536.

113. Mortimer JA, Petersen RC: Detection of prodromal Alzheimer's disease. Ann Neurol 2008, 64:479-480.

114. Sloane PD, Zimmerman S, Suchindran C, Reed P, Wang L, Boustani M, Sudha S: The public health impact of Alzheimer's disease, 2000-2050: potential implication of treatment advances. Annu Rev Public Health 2002, 23:213-231.

\section{Pre-publication history}

The pre-publication history for this paper can be accessed here: http://www.biomedcentral.com/1741-7015/8/89/prepub

doi:10.1186/1741-7015-8-89

Cite this article as: Forlenza et al:: Diagnosis and biomarkers of predementia in Alzheimer's disease. BMC Medicine 2010 8:89.

\section{Submit your next manuscript to BioMed Central and take full advantage of:}

- Convenient online submission

- Thorough peer review

- No space constraints or color figure charges

- Immediate publication on acceptance

- Inclusion in PubMed, CAS, Scopus and Google Scholar

- Research which is freely available for redistribution

Submit your manuscript at www.biomedcentral.com/submit
C Biomed Central 